Estudios Románicos, Volumen 30, 2021, pp. 103-120

ISSN: 0210-4911

eISSN: 1989-614X

DOI: https://doi.org/10.6018/ER.471941

\title{
A INTENSIFICAÇÃO EM PORTUGUÊS EUROPEU - ALGUMAS CONFIGURAÇÕES LINGUÍSTICAS EM COMENTÁRIOS EM LINHA*
}

(Intensification in European Portuguese some linguistic configurations in online comments)

\author{
Helena Topa Valentim** \\ Faculdade de Ciências Sociais e Humanas. Universidade NOVA de Lisboa/CLUNL \\ Matilde Gonçalves*** \\ Faculdade de Ciências Sociais e Humanas .Universidade NOVA de Lisboa/CLUNL
}

\begin{abstract}
This study focuses on intensification in European Portuguese. Its aim is to identify and describe some linguistic configurations in online comments, which, in conjunction with the discursive-textual characteristics, converge for the characterization of this textual genre. In this perspective, the intensification is approached here as a discursive-textual phenomenon, with a focus on the relevance that linguistic forms and constructions have as markers of values of a high degree of a property or of an effect of meaning along with the strong manifestation of the subject, which is, in itself, a characteristic of the commentary genre.
\end{abstract}

Keywords: comment; intensification; linguistic configurations.

Resumo: No estudo aqui proposto sobre a intensificação em português europeu, pretende-se identificar e descrever algumas configurações linguísticas em comentários em linha, que, em articulação com as características discursivo-textuais, convergem para a caracterização deste género. Nesta perspetiva, a intensificação é abordada enquanto fe-

\footnotetext{
* O presente trabalho é financiado por fundos nacionais portugueses, através da FCT - Fundação para a Ciência e Tecnologia, como parte do projeto do Centro de Linguística da Universidade NOVA de Lisboa - UID/ LIN/03213/2020.

** Endereço para correspondência: Helena Topa Valentim - Departamento de Linguística, Faculdade de Ciências Sociais e Humanas, Universidade NOVA de Lisboa, Avenida de Berna, 26C/ 1069-061 Lisboa - Portugal (ht. valentim@fcsh.unl.pt).

${ }^{* * *}$ Endereço para correspondência: Matilde Gonçalves - Departamento de Linguística, Faculdade de Ciências Sociais e Humanas, Universidade NOVA de Lisboa, Avenida de Berna, 26C/ 1069-061 Lisboa - Portugal (matilde. goncalves@fcsh.unl.pt).
} 
Helena Topa Valentim / Faculdade de Ciências Sociais e Humanas. Universidade NOVA de LisboalCLUNL Matilde Gonçalves / Faculdade de Ciências Sociais e Humanas . Universidade NOVA de Lisboa/CLUNL

nómeno discursivo-textual, com um enfoque na relevância que as formas e construções linguísticas têm enquanto marcadoras de valores traduzíveis num grau elevado de uma propriedade ou de um efeito de sentido a par com a forte manifestação do sujeito, uma característica do género comentário.

Palavras-chave: comentário; intensificação; configurações linguísticas.

\section{Introdução}

É objetivo deste trabalho' dar conta de algumas configurações linguísticas relativas à intensificação em português europeu em comentários em linha. Para tal, conjugamos o estudo das configurações linguísticas, a perspetiva da Teoria Formal Enunciativa (Culioli), com a análise da organização discursivo-textual na esteira dos trabalhos de Voloshinov ([1929]1977) e Bronckart (1997), convocadas nos comentários. A natureza conciliadora da nossa abordagem advém de três assunções: 1) analisar textos empíricos equivale a utilizar instrumentos que destacam os diversos recursos linguísticos convocados e sua variabilidade; 2 ) a análise de textos circulando em práticas sociais de linguagem e pertencendo a um determinado género motiva o desenvolvimento de instrumentos de análise operacionais que deem conta dos textos enquanto objetos empíricos e complexos; 3) as configurações linguísticas e a diversidade dos valores construídos inscrevem-se sempre numa atividade de linguagem cuja descrição convoca as diversas dimensões da análise textual.

Voloshinov demonstrou queas práticas sociais influem na organização e na construção linguística e textual enformando os enunciados e os textos: «chacun des types de communication sociale [...] organise, construit et achève, de façon spécifique, la forme grammaticale et stylistique de l'énoncé ainsi que la structure du type dont il relève» (Voloshinov [1929]1977: 289-290). Para além disso, estruturou um programa metodológico descendente ([1929]1977:137-139) com vista ao estudo das atividades sociais de linguagem, a seguir ao dos géneros e finalmente ao das estruturas linguísticas. Este método de análise é o mais adequado para o nosso trabalho, tendo em conta que permite determinar o objeto a analisar quer ao nível macro (global), quer ao nível micro (local). Da nossa parte e perante o programa descendente, optamos por uma metodologia dialética que estabelece um diálogo entre a vertente macro e micro, e vice-versa, atendendo a que o estudo das configurações linguísticas, a saber os valores semânticos construídos ao nível micro torna possível uma melhor apreensão do nível macro (atividade de linguagem, género e texto).

Este artigo, para além da introdução e das notas conclusivas, organiza-se em torno de 3 partes assim identificadas: a intensificação linguística - representação da excelência de um valor, em torno dos comentários e análise da intensificação num corpus de comentários em linha.

\footnotetext{
1 O estudo proposto no presente artigo insere-se nas atividades relativas à abordagem das práticas de comentário desenvolvidas pelo grupo de investigação Gramática e Texto do Centro de Linguística da Universidade de Nova de Lisboa, visando a análise do corpus G\&T.comenta, com vista à categorização do comentário enquanto atividade de linguagem e prática textual.
} 


\section{Intensificação linguística - representação da excelência de um valor}

A questão da intensificação sempre suscitou interesse, e continua a suscitar como o demonstra a coletânea de artigos em que o presente artigo se insere. Dos diversos trabalhos sobre esta questão (Bordet e Jamet, 2015; Carreira (dir.), 2004; Romero, 2007, 2017, a título de exemplo), ressalta a variedade dos termos, bem como a heterogeneidade dos fenómenos linguísticos que expressam a intensificação.

Com vista a um melhor conhecimento da noção em causa, e consequentemente a uma harmonização das noções e dos fenómenos envolvidos, foi publicado um número da Langue Française ( $\left.{ }^{\circ} 177,2013\right)$, sob a coordenação de Jean-Claude Anscombre e Irène Tamba, intitulado Autour du concept d'intensification. Nele convergem as diversas abordagens sob as quais a intensificação pode ser equacionada. Numa perspetiva descritiva, são elencadas as diversas expressões dos fenómenos intensivos aos níveis lexical, semântico-sintático, prosódico e enunciativo-argumentativo. Segundo uma abordagem metalinguística, é possível observar que as categorias utilizadas são flutuantes, indo da intensidade à intensificação, mas abrangendo também o alto grau, a quantidade / quantificação e a escalaridade. Intensidade e intensificação são igualmente passíveis de ser observadas segundo uma abordagem lexical, na qual a intensidade seria uma noção metalinguística e a intensificação uma categoria linguística (Kleiber 2013). Finalmente, é de sublinhar a abordagem proposta por Romero (2007), na qual se perspetiva uma definição mais global do fenómeno da intensidade, partindo da observação do desvio quantitativo e qualitativo entre dois pólos.

Ainda a propósito das abordagens mais frequentes da intensificação linguística, encontra-se a descrição semântico-formal, que tende a circunscrever este fenómeno a um nível de manifestação morfo-lexical. Neste ponto de vista, a intensificação linguística consiste num processo semântico marcado pelo uso de advérbios, adjetivos (e seus diferentes graus), pela gradação e repetição de substantivos, e assim por diante. Um exemplo desta perspetiva são os estudos sobre a intensificação em inglês de Quirk (1988). O autor distingue três subclasses de "intensificadores", destes resultando seja um efeito de amplificação seja um efeito de diminuição de uma propriedade. São essas subclasses, respetivamente as dos "intensificadores", "amplificadores" e "redutores".

Outras abordagens relacionam esses fenómenos com as estratégias de organização informacional do texto, ultrapassando, assim, o nível morfo-lexical e reconhecendo o papel essencial da troca interativa. Por exemplo, numa perspetiva funcional (de acordo com Halliday \& Hasan 1976, e com Halliday 1985), a intensificação está ligada às funções informacionais, textuais e interpessoais.

Tendo em conta o apresentado anteriormente, a perspetiva que adotamos visa descrever e compreender os fenómenos de intensificação em comentários em linha, sustentada numa análise das configurações linguísticas sob o referencial da Teoria Formal Enunciativa, um modelo descritivo e explicativo baseado em operações predicativas e enunciativas, que implica um entendimento da linguagem enquanto atividade cognitiva de representação simbólica.

Nesta perspetiva, eminentemente cognitiva, enfatiza-se o processo dinâmico da atividade mental que subjaz à pluralidade dos fenómenos linguísticos que marcam a construção de 
uma intensificação. Os falantes dispõem de dispositivos cognitivos que lhes permitem proceder a ajustamentos intersubjetivos e discursivo-textuais. A atividade linguística - enquanto atividade representacional e reguladora e de semiotização - está, pois, constantemente submetida a vários constrangimentos de origem sócio-cultural. Da compreensão da linguagem como uma atividade com essas três dimensões - (segundo Antoine Culioli) representação, referenciação e regulação - resulta que a linguagem é, em certo sentido, um sistema simbólico autónomo. Cria uma ordem própria, não decalca (não segue de perto) aquilo que possamos considerar como realidade. Não transpõe nada; antes cria. É por isso que lhe está subjacente uma base cognitiva, informada, é claro, por restrições sócio-culturais ao nível da configuração das noções, enquanto «feixe de propriedade físico-culturais» (Culioli 1981: 53-54).

Cada unidade linguística pode ser considerada o resultado material (portanto, acessível) de uma cadeia complexa de operações mentais. Neste processo, há sempre reconstrução, ajuste, equivalência e alternância, com base em alguns conceitos cognitivos basilares, ou primitivos. Cada vez que construímos um termo linguístico, ativamos um conjunto de operações cujos traços permanecem no discurso.

Em termos gerais, temos sempre um esquema de individuação, que consiste na passagem de uma noção, isto é, um conjunto estruturado de propriedades físicas e culturais, para uma ocorrência linguística (portanto, ocorrência de uma noção). A noção, que tem uma dimensão estritamente qualitativa, quando localizada em relação a um sistema referencial, cujos parâmetros são o sujeito (S) e o espaço-tempo (T), ganha, por conseguinte, valores referenciais.

Assim, uma ocorrência associa necessariamente à qualidade nocional inicial, um QUALE, ou seja, a delimitação, por parte de um sujeito enunciador, de um QUANTUM temporal-aspetual. Tal delimitação não se refere ao mundo físico, aos objetos materiais fenomenologicamente considerados. É antes uma forma de construir representações, mais propriamente, representações linguísticas (Culioli 1992: 109).

Esta passagem do qualitativo estrito (da noção) ao quantitativo (à ocorrência) corresponde a uma operação cognitiva de fragmentação. Por meio dessa operação, a noção prepara-se para fornecer ocorrências localizadas: temos, pois, a passagem da noção para um domínio nocional, que integra ocorrências abstratas (ocorrências possíveis, ou virtuais, da noção).

Quais as operações cognitivas que subjazem à construção de intensificação linguística?

Tomemos como exemplo a sequência É preciso uma paciência!, adaptada de Culioli 1992 (Marie a une telle pacience!). Contrói-se, neste caso, "um grau de paciência", "uma variedade de paciência", de que o artigo indefinido "uma" é o marcador linguístico. Opera-se, por conseguinte, uma fragmentação, condição para que se identifique e localize uma ocorrência ("É preciso"). Além da operação de fragmentação, opera-se, igualmente, uma construção de alto grau, isto é, de um grau extremo e assim se constrói um valor intensificacional.

Esta representação da excelência de um valor por via da sua intensificação não é diretamente acessível. Ela serve como um centro organizador das ocorrências nocionais e regula a sua organização. É um ponto fixo, o centro atrator. E assim, tais ocorrências são, não apenas espacio-temporalmente localizadas (em relação a um sistema referencial) (a um QUANTUM), mas também subjetivamente localizadas no seu domínio de 
ocorrência (ou QUALE) (Culioli, ibidem).

Uma consequência teórica deste funcionamento é o facto de não haver ocorrências isoladas; qualquer ocorrência está localizada em relação a outra ocorrência. Nos casos em que temos intensificação linguística, a ocorrência construída linguisticamente situa-se em relação ao atrator - um centro organizador que, por natureza, é o indizível, o imensurável. Constrói-se um acontecimento imaginário, que é uma representação cognitiva de todos os valores possíveis de "paciência", e que constitui uma representação instável, por ser uma representação construída subjetivamente.

Assim, as ocorrências de uma noção são construídas na sua variabilidade, ou grau de adequação em relação àquele valor absoluto que reenvia para a própria noção, nas suas propriedades intensionais. A intensificação prende-se, pois, com a intensidade de uma propriedade construída como graduável. A ocorrência linguística é, no caso, localizada em relação a um atrator, de natureza qualitativa que tem como característica ser inacessível. Trata-se, no que à construção da significação diz respeito, do regulador imaginário das representações que construímos (Culioli 1995).

Pelo facto de se estar perante a construção de ocorrências linguísticas cuja localização se dá por referência ao atrator do domínio nocional, a intensificação linguística é, enquanto representação, instável, construída subjetivamente, ativando valores que se prendem com valorações do caráter agradável ou desagradável, favorável ou desfavorável, do conteúdo proposicional para o sujeito enunciador, em virtude do também construído valor de modalidade apreciativa. É, aliás, exatamente em função da constância e da relevância deste ponto de vista do enunciador que temos, nos enunciados em que se constrói intensificação, a marcação de modalidade apreciativa.

Como tal, o fenómeno linguístico da intensificação ilustra a capacidade reguladora da linguagem, como atividade por via da qual se operam múltiplos ajustamentos subjetivos. O domínio da regulação, da representação linguística de algo instável, convoca a relevância da coordenada subjetiva como ancoradouro da construção dos valores. Deste modo, com vista à descrição e explicação da intensificação, há que ter presente que a marcação da intensidade de uma propriedade graduável se dá no quadro da modalidade linguística. Mais propriamente, quando se dá a intensificação, é por referência ao sujeito enunciador que se constroem valores graduáveis, no caso, valorativamente graduáveis, já que este veicula, por esta via, um ponto de vista valorativo, que corresponde, como dizíamos, a um valor de modalidade apreciativa. Ao nível da modalidade apreciativa, que consiste na representação linguística da forma como o sujeito enunciador perspetiva o conteúdo proposicional em termos valorativos, encontramos a marcação linguística do caráter agradável ou desagradável, favorável ou desfavorável, do conteúdo proposicional, característica confirmadamente presente em textos do género comentário, como os dados em análise atestarão.

\section{Em torno do(s) comentário(s)}

A atividade de comentar é considerada como comum ao ser humano, nela se podendo cumprir uma função de desambiguação e de elucidação de um enunciado (Blom 
2017). Os diversos trabalhos relativos ao comentário (Boulègue 2014, Calabrese 2019, Goulet-Cazé (dir.) 2000) evidenciam uma multiplicidade de aceções e uma grande oscilação no que toca à forma de denominar as práticas de comentário. Glosa, comentário, marginália ou escólios, no que se prende com a práticas mais antigas de opinião, comentário de leitor, comentário de especialista, para as mais recentes demonstram a existência de um agrupamento de diversas características sob uma denominação comum. É igualmente de realçar que, observando a história do comentário, facilmente se depreende que este evoluiu ao longo do tempo no respeitante ao âmbito do estudo e/ou de circulação. Se, em tempos, o comentário circulava no seio da literatura, da exegese dos textos bíblicos, da filosofia ou ainda da ciência, a chegada e a expansão do digital promoveu a apropriação do comentário nas esferas jornalísticas e do quotidiano (Gonçalves e Carrilho 2020, Teixeira 2016).

Embora se possa elencar os aspetos diferenciadores das práticas de comentário, importa igualmente destacar os aspetos comuns. O primeiro a ser destacado diz respeito à sua natureza intertextual. De facto, um comentário convoca necessariamente uma reação, materializada por um texto, a um objeto textual ou a um evento, a qual se pode realizar através de uma especificação ou de uma diversificação do conteúdo apresentado no texto fonte. $\mathrm{O}$ segundo aspeto incide sobre o caráter normativo dos comentários (Calabrese 2019). Com efeito, tal como apontado por Foucault (1971) e por Bronckart e Bulea (2006), os comentários possuem a capacidade de regular e de estruturar as atividades humanas. $\mathrm{O}$ terceiro e último diz respeito à manifestação do sujeito enunciador na materialidade textual. De facto, as práticas jornalísticas convocam diversos modos de textualizar. A partir do Livro de Estilo do jornal Público e da obra editada por Maltais (2010), é possível dividir esses modos em três: 1) apresentação dos factos e transmissão de informação com base na opinião de terceiros; 2) relacionamento dos factos a partir de uma interpretação dos mesmos pelo produtor textual (neste caso jornalista); 3) construção de um juízo de valor sobre os factos. O comentário rege-se pelo terceiro modo, manifestando um posicionamento do sujeito enunciador, marcado por diversas formas, também de natureza diferente, com relevo para a sua natureza morfossintática, semântica e discursiva, conforme se demonstrará no ponto 4 do presente trabalho. No caso dos comentários na esfera do quotidiano e das redes sociais, diversos trabalhos apontam para um ethos manifestamente presente (Rosier 2015) e para uma ampliação da vertente narcisista dos autores (Chanay e Rosier 2016). Importa ainda realçar a perspetiva de Broucker (1995), retomada por Adam (1997), segundo o qual o objetivo do comentário é o de fazer valer o ponto de vista, bem como o de se tomar posição através de uma implicação enunciativa e de um envolvimento maior por parte do sujeito enunciador. Perante estas características do comentário, depreende-se, naturalmente, que a intensificação será um recurso relevante neste género.

\subsection{Os textos em análise}

Este artigo integra o projeto G\&T.Comenta e os exemplos estudados pertencem ao corpus do projeto, constituído por mais de 700 textos, circulando em diversos 
contextos - académico, jornalístico, político, quotidiano ${ }^{2}$. Para o presente trabalho, optamos por um número assumidamente reduzido de textos - 4 -, tendo em conta a riqueza das configurações linguísticas relativas à intensificação. Assim, 2 dos textos circulam na rede social Facebook, um deles na página do jornal $O$ Mirante e o outro na página de uma personalidade política (António Costa, o atual Primeiro Ministro Português); o terceiro texto pertence à revista Visão, versão em linha, e corresponde aos comentários em caixa relativos a um texto de opinião de Ricardo Araújo Pereira; o quarto texto é oriundo de um jornal quotidiano, o Público, da autoria de Sofia Lorena.

Organizamos os textos a partir de uma numeração de 1 a 4, como a seguir se apresenta. A mesma será retomada na análise, correspondendo à notação final dos exemplos (ponto 4).

O texto 1 circula no sítio web do jornal Público e intitula-se $O$ novo faraó esvaziou o Tahrir, disponível em :https://projetos.dhlab.fcsh.unl.pt/s/GTComenta/item/4618

$\mathrm{O}$ texto 2 "O governo vai apresentar a candidatura do Eng. ${ }^{\circ}$ António Guterres a Secretário Geral das Nações Unidas" faz parte da rede social Facebook, com formato caixa de comentários, disponível em https://projetos.dhlab.fcsh.unl.pt/s/GTComenta/ $\underline{\text { item } / 3967}$

Os comentários do texto 2, Assim também eu da revista Visão, pertencem ao formato Caixa de comentários e estão disponíveis em: https://projetos.dhlab.fcsh.unl.pt/s/ GTComenta/item/3853

Os comentários do texto 4, intitulado Sónia Sanfona retirada da lista do PS por Santarém critica secretário-geral, do jornal O Mirante, pertencem ao formato Caixa de comentários e circula na rede social Facebook, disponível em https://projetos.dhlab. fcsh.unl.pt/s/GTComenta/item/4142

\section{Análise da intensificação num corpus de comentários em linha}

Da análise da heterogeneidade de formas e de construções linguísticas do corpus em apreço que marcam intensificação, parecem destacar-se como denominador comum dois aspetos estritamente relacionados. São eles, por um lado, a construção de ocorrências linguísticas cuja localização se dá por referência ao atrator do domínio nocional; por outro lado, a construção de modalidade de valor apreciativo, mediante o qual o sujeito enunciador sinaliza o caráter agradável ou desagradável, favorável ou desfavorável, do representado ao nível do conteúdo proposicional.

A intensificação assim perspetivada surge, no corpus de comentários em linha analisado, marcada de várias formas: por construções de alto grau, por construções a que subjaz uma operação de percurso com/sem fixação de um valor, por construções em que se dá uma transferência nocional e, finalmente, por construções que sinalizam a conformação a um pré-construído, um padrão expectável.

2 Para mais informações relativas ao corpus e à etiquetagem dos textos cf. Gonçalves e Carrilho (2020). 
Helena Topa Valentim / Faculdade de Ciências Sociais e Humanas. Universidade NOVA de LisboalCLUNL Matilde Gonçalves / Faculdade de Ciências Sociais e Humanas . Universidade NOVA de Lisboa/CLUNL

Passamos a percorrer cada um destes tipos de situações atestadas no corpus com sequências de que nos valeremos como forma de exemplificação ${ }^{3}$.

\subsection{Construções de alto grau}

São vários os processos de construção do alto grau de propriedades, que não apenas o recurso à variação morfossintática de grau superlativo. Comecemos, ainda assim, por este caso, em que a intensificação se encontra marcada pelo grau superlativo absoluto de uma forma adjetival. Por exemplo em:

1. Têm sido os piores anos de sempre, piores do que os meses de Morsi, piores do que Mubarak. (1.6)

2. Cavaco e Marcelo são parecidíssimos e, no entanto, Marcelo consegue ser o antiCavaco. (2.2)

3. É forte convicção do Governo que o Eng ${ }^{o}$ António Guterres é a personalidade com as melhores condições para exercer esse mandato. (3.1)

4. O mais engraçado é que quem escolhe é uma pessoa que nem devia lá estar. LOL continuamos a ser uma «república das bananas», não vamos a lugar nenhum assim. (4. 4)

5. O mais grave é que todos os anos há um lapidar de alguma coisa. (4.6)

Nas sequências 4 e 5, de forma particular, a construção superlativa recai sobre a expressão linguística do ponto de vista apreciativo do sujeito enunciador sobre o conteúdo proposicional que se vê, deste modo, intensificado como sendo ironicamente engraçado $(4)^{4} \mathrm{e}$, sem ironia, grave (5).

Este mesmo valor de alto grau encontra-se em construções intensificadoras da propriedade da noção, tais como aquela em que ocorre o elemento intensivo tão (ou tanto), que pede uma oração consecutiva. Por exemplo:

6. Também deve ser por ele [Ricardo Araújo Pereira] ser tão soporífero que o sr. ficou tão adormecido que se deu ao trabalho de vir aqui exprimir a sua opinião. (2.4)

Também a comparação se afigura como construção linguística de intensificação quando o segundo termo da mesma corresponde a algo considerado, no universo do

3 Os exemplos contêm, além da numeração decorrente da ordem pela qual aqui são apresentados, um índice numérico que permite identificá-los no interior do corpus de análise constituído para este estudo (ponto 3.1). Esta notação encontra-se no fim de cada sequência. Quando o mesmo exemplo sirva para ilustrar diferentes construções, procede-se à sua retoma, mas com nova numeração, coerente com a ordem de apresentação de cada um dos tipos de marcação linguística do fenómeno de intensificação. Os enunciados são transcritos conforme a sua forma original, em termos de pontuação e de ortografia. Optou-se igualmente por sublinhar, nalguns exemplos, as formas referentes ao que se pretende colocar em destaque na análise proposta.

4 Como veremos adiante, a ironia, enquanto recurso discursivo, também contribui para a construção de uma intensificação. 
discurso, um caso extremo, eventualmente correspondente a algo que roce mesmo o patético, numa expressão inequívoca do ponto de vista crítico do enunciador. Veja-se o exemplo 7:

7. Suceder a Cavaco Silva na presidência é como casar em segundas núpcias com Tina Turner. Depois daquele primeiro marido, qualquer homem é um príncipe. (2.1)

O nivelamento operado pela comparação (é como) comporta um juízo valorativo, que, neste enunciado, é corroborado na sequência que assume uma função reformulativa de valor parafrástico, nomeadamente no recurso à expressão um príncipe, metáfora que sublinha o alto grau construído no primeiro termo da comparação (Suceder a Cavaco Silva na presidência).

No exemplo 8, o já alto grau marcado pela comparação (melhor) estabelecida vê-se intensificada através do adverbial que marca a construção de um valor modal epistémico de certeza, de asserção portanto:

\section{Seguramente melhor que o atual. (3.4)}

Por conseguinte, a comparação nos termos descritos reverte para a intensificação do ponto de vista do sujeito relativamente ao primeiro termo da mesma.

Um outro fenómeno, característico do português, o recurso ao diminutivo com um valor discursivamente pejorativo, regista um índice de frequência muito elevado no corpus de comentários em linha observado, ao ponto de merecer uma referência e a exploração em trabalhos futuros da especificidade do seu emprego como característica deste género textual. Consiste numa formação morfológica derivacional comummente associada a grau num sentido de ordem de grandeza mas que, em português, se comporta como um avaliativo. Vejam-se as seguintes ocorrências:

9. A «guerrinha» dos lugares no partido, para aferir que fica com o tacho pago por todos nós! (4. 9)

10. Continuem a votar e a andar com as bandeirinhas nas mãos!!! Uma vergonha...(4. 21)

11. Tachos e tachinhos, mais nada. (4. 28)

12. Coitadinha dela! Temos pena. [...] Acabou o tacho, minha senhora, faça-se à vida! (4. 30)

Com um sentido claramente pejorativo, as ocorrências de formas diminutivas sublinham, por via de processos discursivos, como seja a ironia (12), e semânticos, como a metáfora, ou transferência nocional (nos casos 9, 11 e 12, consagrada pelo uso), a construção de um valor de alto grau das propriedades associada às noções lexicalizadas nos nomes guerra (9), bandeira (10), tacho (11) e no adjetivo coitada (12). Deste modo se intensifica, com um valor de modalidade apreciativa, a significação construída.

A anteposição do adjetivo, em virtude do valor construído por referência ao sujeito enunciador, também converge para a construção de intensificação do grau de proprie- 
Helena Topa Valentim / Faculdade de Ciências Sociais e Humanas. Universidade NOVA de LisboalCLUNL Matilde Gonçalves / Faculdade de Ciências Sociais e Humanas . Universidade NOVA de Lisboa/CLUNL

dades que definem intensionalmente a noção lexicalizada pelo adjetivo. Veja-se os seguintes exemplos:

\section{Um grande senhor! (3.6) \\ 14. Que grande timing, hein, Costa. (3.5)}

\section{2 Operação de percurso com/sem fixação de um valor}

São inúmeros, no corpus de comentários em linha observado, os enunciados em que a intensificação se constrói por via da construção de uma operação de percurso que culmina seja na construção de um valor de polaridade negativa, seja num valor de totalização, seja ainda num valor de unicidade.

Como exemplos de construção de polaridade negativa, atentemos nos seguintes enunciados:

15. Nem uma bandeira, uma faixa, nem um manifestante. ( ${ }^{a}$ col., l. 28-29) (1.3)

16. Este palhaço que nem graça tem nos anúncios da MEO, também se julga alguém importante. (2.3)

17. Isto é que vai uma açorda!!!!!! Não se entendem nem a eles próprios. (4.10)

18. Votação democrática? E há disso nos «interesses» partidário e lobies nacionais, distritais ou concelhios??! Nem nas freguesias, quanto mais...! (4.13)

19. Tachos e tachinhos, mais nada. (4.28)

Subjaz a esta construção de polaridade negativa uma operação de percurso por todas as ocorrências abstratas da noção para, extraindo uma, sobre ela se construir uma negação. A não validação dessa ocorrência torna-se, deste modo, numa forma de intensificação, no caso, de exclusão absoluta de qualquer hipótese de validação de uma ocorrência que seja da noção, isto é, da validação mínima.

A noção sobre a qual recai esta operação pode ser de natureza lexical $(15,16$ e 17) ou de natureza complexa, envolvendo um conteúdo proposicional (18 e 19).

Nos enunciados que se seguem, a operação de percurso sobre a totalidade das ocorrências abstratas da noção salda-se na validação dessa mesma totalidade, daí resultando um valor de intensificação, a que, no caso do enunciado 21 , se associa um sentido irónico:

20. Sissi secou tudo. (2 ${ }^{a}$ col., l. 19) (1.5)

21. Tudo em nome da Democracia...(4.37)

Este valor de totalização polarizada, isto é, absoluta, reveste-se de uma dimensão quantitativa. Já os enunciados que se seguem ilustram uma terceira situação, em que o valor de intensificação tem subjacente uma operação de percurso mas daí se extraindo uma única, exclusiva, ocorrência linguística da noção, que se reveste seja de uma dimensão quantitativa (22, 23 e 25) seja de uma dimensão qualitativa (24 e 26): 
A intensificação em português europeu - Algumas configurações linguísticas em comentários em linha

22. Eram tempos de esperança e de resistência: num só domingo, 22 de novembro de 2011, pelo menos 24 pessoas eram mortas a tiro ou asfixiadas. (1.1)

23. Foi o único que admitiu não querer movimentar-se no "pântano». (3.3)

24. Neste processo só lamento que o Presidente da Federação Distrital de Santarém não tivesse a atitude que teve o Álvaro Beleza. (4.2)

25. O único objetivo é sugar o erário público a bem do interesse pessoal! (4.25)

26. Os Partidos são tudo menos democráticos (4.33)

A unicidade resulta de uma operação de percurso que culmina na extração de uma ocorrência que é validada pelo enunciador como sendo a única. Daí advém uma intensificação com um valor de modalidade apreciativa. A apreciação em causa por parte do sujeito pode corresponder, do ponto de vista discursivo, a um juízo de exaltação ou a um juízo de indignação relativamente ao conteúdo proposicional. É a valoração favorável (23) ou desfavorável $(22,24,25$ e 26) do conteúdo proposicional que assim o dita.

\subsection{Transferência nocional}

O valor de intensificação pode ser marcado com recurso a uma outra noção, metaforicamente relacionada com a noção em causa, isto é, com propriedades comuns ou aproximáveis, e com um ganho em termos de intensificação. Com a finalidade de se construir um alto grau da propriedade da noção, a transferência nocional ativa a construção de um valor já não lexicalizável senão no exterior do domínio, recorrendo-se, desta feita, a outra noção, que comporta propriedades aproximáveis mas simultaneamente diferentes ainda que intensificadoras da propriedade cujo alto grau se quer construir. Vejam-se alguns exemplos:

27. Este palhaço que nem graça tem nos anúncios da MEO, também se julga alguém importante. (2.3)

28. Isto é que vai uma açorda!!!!!! Não se entendem nem a eles próprios. (4.10)

29. A "guerrinha» dos lugares no partido, para aferir que fica com o tacho pago por todos nós! (4.9)

30. Em vários distritos do país alguns socialistas estão a ficar em estado de choque. Tanta vontade em servir o país e, particularmente, a região pela qual pretendem ser eleitos. Só pode ser isso. Pena é que quando são eleitos se esqueçam rapidamente dos seus distritos e dos seus eleitores. (4.16)

31. Confirma-se o jogo de interesses da classe politica (4.18)

32. Realmente é triste ver este espetáculo. (4.22)

33. O único objetivo é sugar o erário público a bem do interesse pessoal! (4.25)

34. Olha só como é que vai ser, a amiga tem que estar na lista (4.26)

35. A luta do tacho. (4.27)

36. Tachos e tachinhos, mais nada. (4.28)

37. Coitadinha dela! Temos pena. [...] Acabou o tacho, minha senhora, faça-se à vida! (4.30) 
Helena Topa Valentim / Faculdade de Ciências Sociais e Humanas. Universidade NOVA de LisboalCLUNL Matilde Gonçalves / Faculdade de Ciências Sociais e Humanas . Universidade NOVA de Lisboa/CLUNL

38. É só tachos (4.31)

39. Acabou-se o tacho (4.32)

40. Já começaram os padrinhos! (4.34)

41. É a dança das cadeiras...(4.35)

42. A luta pelo poleiro... (4.36)

Trata-se, como se pode verificar pela diversidade de ocorrências, de um tipo de construção muito frequente, em virtude da expressividade que comporta, no sentido de marcar a intensificação, apreciativamente construída pelo enunciador. Está-se perante o recurso a expressões consagradas pelo uso, que fazem, portanto, parte do universo discursivo partilhado coletivamente, o que acarreta um grau elevado de irrefutabilidade, por via do qual o valor assim construído se intensifica. A polifonia (Ducrot 1987) aqui manifesta, na convocação de discursos que circulam e da apropriação linguística destas expressões para veicular universos discursivos que transcendem o sujeito, reforça um ponto de vista, em todos os casos aqui ilustrados, de crítica, de indignação mesmo. Trata-se, pois, de um recurso que, inclusivamente pela brevidade, determina a orientação do comentário, permitindo mesmo, em alguns casos, situá-lo do ponto de vista ideológico. Cada expressão funciona como uma espécie de palavra-chave do sentido veiculado no ato de comentar: nestes casos, criticando, denunciado de forma indignada um estado de coisas.

A intensificação por via do recurso a um universo de discurso coletivo encontra-se igualmente presente nos seguintes exemplos:

43. O poder cega as pessoas. Tenham um pouco de vergonha. (4.8)

44. Quem tem olho é rei... (4.12)

45. O caso Sanfona... fecha-se uma porta abre-se outra! (4.15)

46. Quem não é por mim é contra mim. (4.17)

Temos, novamente, expressões consagradas pelo uso coletivo, neste caso, provérbios ou adágios, que, concentrando um conteúdo proposicional validado por um coletivo de enunciadores abstrato - a voz da sabedoria popular - e tido por isso como irrefutável, o enunciador faz reverter, em termos de modalidade, numa validação reforçada. Assim se dá a intensificação, sempre veiculando uma apreciação, que se traduz para o enunciador, em todos estes casos, numa denúncia e manifestação de discordância ou mesmo de indignação relativamente ao objeto do comentário.

\subsection{Conformação a um padrão}

Com o objetivo de reforçar a validação do conteúdo proposicional e de intensificar o valor apreciativo veiculado, o sujeito enunciador socorre-se de diferentes formas e construções linguísticas que marcam a conformação a um saber que ele mesmo constrói como partilhado, deste modo ficando excluída a hipótese de outros valores. Isso mesmo se verifica nos enunciados que se seguem, ainda que em cada um de modo diferente: 
47. O típico do PS, o pessoal das autarquias ganha votos, e depois são excluídos a seguir (4.3)

48. Realmente é triste ver este espetáculo. (4.22)

Afirmar a tipicidade (47) ou recorrer a uma forma como realmente (48), que reforça a validação do conteúdo proposicional, coincidem numa remissão para um padrão coletivamente considerado, daí resultando uma intensificação.

O mesmo padrão pode corresponder a algo da ordem do expectável, mas no sentido daquilo que é tido pelo sujeito enunciador como favorável, ou positivo. Isso mesmo se passa na seguinte sequência, em que à forma interrogativa subjaz uma asserção com valor negativo. Temos, por conseguinte, uma pergunta retórica que realça, ou intensifica, o valor eufórico, ou de exaltação, presente no comentário:

49. De facto, tendo em conta o estado do mundo, quem melhor que o ex-ACNUR para Secretário Geral da ONU... (3.2)

O expectável, esse valor em relação ao qual se constrói uma conformação, confirmativa ou infirmativa, pode ainda caracterizar-se por um valor tido para o sujeito enunciador como desfavorável, ou negativo, isto é, um estado de coisas negativamente apreciado pelo sujeito. Neste caso - conforme ilustrado nos exemplos que seguem - o comentário pauta-se pela expressão de uma indignação, por via da intensificação que resulta desta conformação a um referencial da ordem do expectável, ele mesmo negativo. Vejam-se os seguintes casos, em que à forma interrogativa subjaz uma asserção - novamente, a pergunta retórica:

50. Partido... para quê? [...] Porque será que não é o povo que escolhe a pessoa, mas o chefão do partido? (4.7)

51. E alguma vez se entenderam? (4.11)

52. Votação democrática? E há disso nos «interesses» partidário e lobies nacionais, distritais ou concelhios??! Nem nas freguesias, quanto mais...! (4. 13)

Nos enunciados que se seguem, também com um sentido de indignação, a intensificação que resulta desta conformação a um referencial da ordem do expectável assume um sentido irónico. A ironia, nestes casos, consiste no sublinhar, ou exacerbar, de um valor extremo, com a finalidade de evidenciar o seu contrário:

53. Mais uma que pensava que tinha lugar cativo!! (4.14)

54. Continuem a votar e a andar com as bandeirinhas nas mãos!!! Uma vergonha... (4.21)

55. Adoro ver esta gente falar de democracia (4.23)

56. Coitadinha dela! Temos pena. [...] Acabou o tacho, minha senhora, faça-se à vida! (4.30)

57.Tudo em nome da Democracia... (4.37) 
Helena Topa Valentim / Faculdade de Ciências Sociais e Humanas. Universidade NOVA de LisboalCLUNL Matilde Gonçalves / Faculdade de Ciências Sociais e Humanas . Universidade NOVA de Lisboa/CLUNL

O sarcasmo presente nos seguintes exemplos veicula um ponto de vista subjetivo - apreciativo, aliás - reforçando, pelo seu caráter mordaz, a indignação, assim intensificada, já que a razão que a justifica se afigura, deste modo, como irrefutável:

58. Olha, a sanfona deixou de tocar!!!! (4.19)

59. Realmente este PS cada vez está mais na mesma!!!! É pena não poder sair o Gameiro... (4.24)

60. Olha só como é que vai ser, a amiga tem que estar na lista (4.26)

61. Quer Sanfonar? Que Sanfone outro! (4.29)

Finalmente, também baseado numa referência a um padrão, no caso do desejável ou considerado adequado pelo sujeito enunciador, destacamos como forma de construir uma intensificação os enunciados cujo valor modal apreciativo incidente sobre um conteúdo proposicional se traduz no que pragmaticamente será um lamento.

62. Em vários distritos do país alguns socialistas estão a ficar em estado de choque. Tanta vontade em servir o país e, particularmente, a região pela qual pretendem ser eleitos. Só pode ser isso. Pena é que quando eleitos se esqueçam rapidamente dos seus distritos e dos seus eleitores. (4. 16)

63. Realmente este PS cada vez está mais na mesma!!!! É pena não poder sair o Gameiro... (4.24)

O valor de modalidade apreciativa aqui construído, que recai sobre um conteúdo proposicional já validado, ou pré-construído, reforça o caráter condenável do estado de coisas que é objeto do comentário.

\subsection{Articulação entre configurações da intensificação e atividade de linguagem}

Ao longo do ponto 4 efetuamos um levantamento e uma descrição das formas e construções de intensificação dos comentários em linha, bem como dos diversos valores. Tendo em conta a natureza abrangente da nossa abordagem, no que segue, pretendemos evidenciar a articulação entre atividade de linguagem, configurações linguísticas e a diversidade dos valores construídos.

No âmbito dos estudos relativos aos comentários, é consensual a ideia da existência de uma grande diversidade, profusão e flutuação de noções e de etiquetas (para uma síntese desses trabalhos cf. Gonçalves e Carrilho 2020). Com efeito, nos comentários de especialidade, nos quais se desenvolve uma atividade reflexiva sobre determinado tema e nos quais se dá uma atividade do intelecto (Lévy 2014), é expectável um posicionamento do sujeito enunciador mais moderado e ponderado. Outro aspeto a ter em conta prende-se com o facto de estes textos serem tendencialmente monologais, ou seja, escritos por uma pessoa. Tal facto foi comprovado com o texto 1, O novo faraó esvaziou o Tahrir, no qual a produtora, Sofia Lorena, jornalista, dá conta da situação do Egipto em 2016, com a tomada do poder por Abdul Fattah al-Sissi. Os aspetos aqui apontados 
esclarecem a razão pela qual, neste texto, ao contrário dos outros três, se encontram somente duas configurações de intensificação: construção morfossintática de grau e operação de percurso, como atestam os exemplos 1, 15, 20 e 22.

Os textos 2, 3 e 4, embora contenham diferenças ao nível do lugar de circulação e dos produtores textuais, apresentam todos uma relação de intertextualidade entre um primeiro texto - fonte dos comentários - e os comentários visíveis em formato caixa de comentário, ou ainda entre os diversos produtores de comentários entre eles. Consequentemente, observa-se, com facilidade, o deslocamento do foco inicial de um texto sobre um outro texto para uma interação entre dois ou mais intervenientes. Fala-se, neste caso, de uma multiplicação em cascata da atividade comentadora (Paskin 2010), promovida pelo quadro "conversacionalizante" (Paveau 2017), oriundo da arquitetura dessas plataformas de comunicação digital. Assiste-se, concomitantemente, a uma junção entre comentário e diálogo (Calabrese 2019), caracterizada pela rápida troca de mensagens, numa lógica de imediatez, como as gralhas, os erros ortográficos evidenciam. É exatamente neste quadro "conversacionalizante" que se constata um incremento das formas e construções de intensificação, conformando o modo como o sujeito enunciador se posiciona perante o que enuncia (modalidade apreciativa), recorrendo igualmente a diversas configurações da intensificação, tal como foi evidenciado anteriormente.

Em suma, estamos em crer que as redes sociais e o formato caixa de comentários (textos 2, 3 e 4), em contraposição com o texto 1, convocam uma maior exposição do sujeito enunciador (Carvalheiro, Prior e Morais 2015). Nesses espaços comunicativos, a construção da identidade do sujeito enunciador passa pela validação valorativa do seu ponto de vista ou a diminuição do ponto de vista do outro (recurso aos diminutivos, à ironia e ao sarcasmo), através da "intensificação" e da "sobrevalorização" da sua perspetiva. Nesse sentido, a abordagem descendente (Voloshinov [1929]1977) revela ser uma abordagem pertinente para a compreensão global dos fenómenos de intensificação.

\section{Reflexões finais}

Foi objetivo deste trabalho explorar algumas configurações linguísticas do fenómeno de intensificação, num corpus de comentários em linha em português europeu. Assumindo que essas mesmas configurações, tendo em conta a diversidade dos valores construídos, se inscrevem necessariamente em esferas e práticas de linguagem diferentes, concilia-se, por um lado, uma abordagem discursivo-textual com, por outro lado, um enfoque na identificação da natureza das formas linguísticas e dos processos, ou mesmo das operações cognitivas, que convergem para a construção da intensificação. Para tal, articulamos o estudo das configurações linguísticas, seguindo a perspetiva da Teoria Formal Enunciativa, com a influência da atividade de linguagem em que os comentários em linha circulam (rede social Facebook e no sítio web de uma revista e de um jornal).

Tendo identificado quatro tipos de processos gerais que se traduzem na construção de intensificação, verificou-se poder associar, a todos eles, dois fenómenos transversais: 
a construção, por um lado, do alto grau de uma propriedade e, por outro, de modalidade de tipo apreciativo. Entre as ocorrências analisadas, identificou-se igualmente dois tipos de construções morfossintáticas características do português, em termos do seu valor expressivo no discurso, que contribuem para um valor de intensidade. São elas o diminutivo, que assume um valor discursivamente pejorativo, e a anteposição do adjetivo, com um valor investido de uma carga subjetiva, permitindo evocar sentidos que servem o fim discursivamente visado de intensificar a manifestação de um ponto de vista.

Destaca-se deste estudo a frequência e também a diversidade de ocorrências, nas práticas de comentário, de configurações linguísticas de que decorre uma intensificação. Enquanto classe de texto que manifesta uma presença do sujeito como responsável por um ponto de vista relativamente a um texto ou a um evento, o comentário regista múltiplas formas de reforço dessa presença. Uma delas, estreitamente ligada, como vimos, com a construção de um alto grau e com a modalidade apreciativa, é a intensificação. Através deste recurso, o sujeito sublinha a veemência do juízo e das considerações que faz relativamente a um texto ou a um evento. Ainda através da intensificação, o mesmo sujeito pretende, por conseguinte, alcançar a expressão de algo por si construído como irrefutável. Apresenta, deste modo, uma forma de validação da sua manifestação subjetiva, alicerçada em convicções como lugar de uma verdade, aquela que o seu ponto de vista sobrevaloriza.

\section{REFERÊNCIAS}

ADAM, Jean-Michel (1997): "Unités rédactionnelles et genres discursifs. Cadre général pour une approche de la presse écrite". Pratiques, n 94. Paris: Nathan: 3-18. Disponível em: http://www.pratiques-cresef.com/p094_ad1.pdf

ANSCOMBRE, Jean-Claude; TAMBA, Irène (dir.) (2013) : "Autour du concept d'intensification". Langue française, 1(1) https://doi.org/10.3917/lf.177.0003

BLOM, Alderik (2017): Glossing the psalms. The emergence of the written vernaculars in western Europe from the seventh to the twelfth Centuries. Berlin/Boston: De Gruyter.

BORDET, Lucile; JAMET, Denis (2015): "Degré et intensification : essai de typologie", Anglophonia [Online], 20 | 2015, Online since 02 November 2015, connection on 27 February 2021. URL:[ http://journals.openedition.org/anglophonia/549]

BOULĖGUE, Laurence (ed.) (2014) : Commenter et philosopher à la Renaissance : Tradition universitaire, tradition humaniste. Villeneuve d'Ascq : Presses universitaires du Septentrion. [https://books.openedition.org/septentrion/5934]

BRONCKART, Jean-Paul (1997) : Activité langagière, textes et discours. Pour un interactionisme socio-discursif. Paris: Delachaux et Niestlé.

BRONCKART, Jean-Paul, BULEA, Ecaterina (2006): "La dynamique de l'agir dans la dynamique langagière”. In J.-M. Barbier \& M. Durand (éds.) Sujet, activité, environnement : approches transverses. Paris: PUF : 105-134. 
BROUCKER, José de (1995): Pratiques de l'information et écritures journalistiques. Paris: CFPJ.

CALABRESE, Laura (2019) : Le commentaire : continuités et mutations d'un outil au service de la lecture et de l'écriture. In Calabrese, L. (coord.) Le commentaire du manuscrit à la toile. Revue de linguistique française et d'analyse du discours. Paris : Editions L'Harmattan. ISBN : 978-2-8066-3700-0: 7-28.

CARREIRA, Maria Helena (dir) (2004) Plus ou moins?! L'atténuation et l'intensification dans les langues romanes. Travaux et Documents 24. Paris: Presses Universitaires de Saint-Denis.

CARVALHEIRO, José Ricardo, PRIOR Hélder, MORAIS Ricardo (2015): "Público, privado e representação online”. In Carvalheiro, José Ricardo (ed.) A nova fluidez de uma velha dicotomia: público e privado nas comunicações móveis. Covilhã: LabCom : 7-27. [http://labcom.ubi.pt/livro/133]

CHANAY, Hugues Constantin de; ROSIER Laurence (2016): "Faces extimes sur Facebook: un point de vue «personnel»", Cahiers de praxématique 66 [http://journals.openedition.org/praxematique/4237]

CULIOLI, Antoine (1981): "Sur le concept de notion". Bulletin de Linguistique Appliqué e Générale, n. 8: 62-79.

(1992): “Un si gentil homme! et d'autres énoncés". L'Information Grammaticale 55, Paris: 59-60.

(1995): Cognition and Representation in Linguistic Theory. Amsterdam / Philadelphia: John Benjamin Publishing Company.

DUCROT, Oswald (1987): O dizer e o dito. Campinas: Pontes. [trad. de Le dire et le dit, 1984]

FOUCAULT, Michel (1971): L'ordre du discours. Leçon prononcée au Collège de France le 2 décembre 1970. Paris: Éditions Gallimard.

GONÇALVES, Matilde; CARRILHO, João (2020): "Comentando comentários: questões de texto, género e corpus". Revista da Associação Portuguesa de Linguística, (7): 191- 208. https://doi.org/10.26334/2183-9077/rapln7ano2020a12

GOULET-CAZÉ, Marie Odile (dir.) (2000): Le commentaire, entre tradition et innovation. Paris: Vrin.

HALLIDAY, Michael Alexander Kirkwood; HASAN, Ruqaiya. (1976): "Cohesion in English". English Language Series, London: Longman.

HALLIDAY, Michael Alexander Kirkwood (1985): An Introduction to Functional Grammar. London: Edward Arnold.

KLEIBER, Georges (2013) : «À la recherche de lintensité »,, Jean-Claude Anscombre; Irène Tamba (dir.). Langue française, 1(1) : 63-76. [https://doi.org/10.3917/ If.177.0003]

LÉVY, CARLOS (2014) : Quelques remarques introductives sur la genèse du commentaire philosophique. In Boulègue, L. (ed.) Commenter et philosopher à la Renaissance. Paris : Presses Universitaires du Septentrion, pp. 19-27. Disponível em : [https://books.openedition.org/septentrion/5937] 
Helena Topa Valentim / Faculdade de Ciências Sociais e Humanas. Universidade NOVA de LisboalCLUNL Matilde Gonçalves / Faculdade de Ciências Sociais e Humanas . Universidade NOVA de Lisboa/CLUNL

MALTAIS, Robert (dir.) (2010): L'écriture journalistique sous toutes ses formes. Montréal: Presses de l'Université de Montréal.

PASKIN, Danny (2010): Say what?. Journal of International Communication, 16:2, pp. 67-83.

PAVEAU, Marie Anne (2017) : L’analyse du discours numérique. Dictionnaire des formes et des pratiques. Paris: Herman.

PÚBLICO (1998): Livro de Estilo do Público. [http://static.publico.pt/nos/livro_estilo/]

QUIRK, Randolph (1988): "Language Varieties and Standard Language". In JALT Journal, Vol. 11. No.1: 14-25.

ROMERO, Clara (2007): "Pour une définition générale de l'intensité dans le langage". Travaux de linguistique, 1(1): 57-68. [https://doi.org/10.3917/t1.054.0057] (2017): L'intensité et son expression en français. Paris: Éditions Ophrys.

ROSIER, Laurence (2015): "L'éthos sur Facebook: de l'interaction à l'autofiction", Johannes Angermuller et Gilles Philippe (dir.), Analyse du discours et dispositifs d'énonciation. Autour des travaux de Dominique Maingueneau. Limoges: Lambert-Lucas: 293-303.

TEIXEIRA, Carla (2016): "Questões de semiótica e de gramática em comentários jornalísticos". Cadernos de linguagem e sociedade, 17(1): 140-161. [https://doi. org/10.26512/les.v17i1.4432]

VOLOSHINOV, Valentin Nikoláievitch ([1929]1977) : Le marxisme et la philosophie du langage. Paris : Minuit.

\section{PERFIL ACADÊMICO E PROFISSIONAL}

Helena Valentim é Professora Auxiliar da Faculdade de Ciências Sociais e Humanas da Universidade NOVA de Lisboa (NOVA FCSH) e Investigadora do Centro de Linguística da Universidade NOVA de Lisboa (CLUNL). Doutorada em Linguística, na especialidade de Semântica, desenvolve investigação nesta área científica, participando em congressos e publicando artigos, nos âmbitos nacional e internacional.

Matilde Gonçalves, doutorada pela Université Paris 8 (Études Portugaises) e pela Universidade NOVA de Lisboa (Linguística - Teoria do Texto), é professora auxiliar na Faculdade de Ciências Sociais e Humanas da Universidade NOVA de Lisboa e investigadora do Centro de Linguística da Universidade NOVA de Lisboa (CLUNL), no qual desenvolve trabalho no grupo Gramática \& Texto. Enquadrado na linguística do texto e do discurso, o seu trabalho centra-se nas práticas de linguagem digitais, na literacia científica e na divulgação de ciência, bem como na transposição de instrumentos linguísticos para fins específicos.

Data de recepção: 02/04/2021

Data de aceitação: 22/05/2021 